\title{
Determinants of Hesitancy to Childhood Immunizations in a Peri -Urban Settlement; A Case Study of Nansana Municipality, Uganda
}

\author{
Amos Kijjambu $^{1 *}$, Edgar Mugema Mulogo ${ }^{2}$ \\ ${ }^{1} \mathrm{MPH}, \mathrm{PhD}$ Candidate, Public Health, Texila American University, Guyana \\ ${ }^{2}$ Professor, Department of Community Health, Mbarara University of Science and \\ Technology, Mbarara, Uganda
}

\begin{abstract}
Vaccine hesitancy to immunization against the childhood vaccine-preventable diseases is increasingly becoming a concern worldwide, which negatively impacts the parents' willingness to vaccinate their children. The objective of this study was to establish the current prevalence of vaccine hesitancy and the factors that determine parent's hesitancy to childhood immunizations in Nansana Municipality, Wakiso District, Uganda. This was a cross-sectional mixed methods study, utilizing both qualitative and quantitative approaches. Evaluation of the determinants of vaccine hesitancy was carried out on 344 parents of children under 24 months, using simple random sampling on pre-tested structured questionnaires. Data was analyzed using SPSS 20.0 software. Additionally, 2 focus group discussions with parents were also conducted. Vaccine hesitancy was found to be 27.6\%. Education level (AOR=4.9, 95\% CI, $2.6-29.5, p=0.01)$, belief in vaccine effectiveness (AOR=0.47, 95\% CI, $0.17-0.97, p=0.01)$, health workers attitude (AOR=0.22, 95\% CI, $0.06-0.86, p=0.03)$, timing of immunization service clinic $(A O R=3.4,95 \% C I, 1.8-6.4, p=0.01)$ and adequate information provision $(A O R=0.64,95 \% C I, 0.16-0.99, p=0.04)$, were the factors that were independently determining vaccine hesitancy. The vaccine hesitancy prevalence rate is comparatively similar to previous urban area studies. Despite parents overwhelmingly believing in vaccines protecting their children from vaccine-preventable disease, these same parents, express concerns regarding timing of the clinic and the side effects of vaccines. There is a need to improve on communication and information flow to address the many vaccine safety concerns, such as side effects.
\end{abstract}

Keywords: Childhood, Determinants, Hesitancy, Immunization, Urban.

\section{Introduction}

Worldwide, the parental vaccine hesitancy to childhood immunizations is a growing problem with a significant public health impact [1], which reflects concerns about the decision to vaccinate their children against the childhood Vaccine-Preventable Diseases (VPDS) [2], yet childhood immunization is a key intervention towards attaining Sustainable Development Goal (SDG) number 3 that aims at reduction of under-five mortality to less than 25/1000 live births by 2030 [3], as immunizations are protective measures against childhood vaccine- preventable infectious diseases [4], and is one of the most cost-effective health investments, with proven strategies that make it accessible to even the most hard-to-reach and vulnerable populations [5], therefore making immunization a reliable child survival strategy, that prevents more than 2.5 million child deaths each year globally [6]. However, worldwide, the VaccinePreventable Diseases (VPDs) burden has remained high, and the immunization coverage rates have plateaued for the last decade, with an estimated 19.7 million children under 1 year not receiving the basic vaccines in 2019 [7]. Approximately 10 million under-five deaths 
occur in low-income countries annually, most of which are from VPDs [8].

Vaccine hesitancy can take different forms, including parents refusing all recommended vaccines or delaying in taking the vaccines due to different reasons $[9,10,11]$. The World Health Organization defines vaccine hesitancy as a "delay in acceptance or refusal of vaccines despite availability of vaccination services [1]. Indeed, the majority of parents agree to vaccinate their children amid concerns [2].

For instance, in a Canadian survey, $70 \%$ of parents were concerned about potential side effects of vaccines, and $38 \%$ believed that a vaccine could cause the disease that it was supposed to prevent [12], while in another study, parents whose children were not immunized cited the lack of perceived necessity of vaccines $(28 \%)$, concerns regarding vaccine safety (17\%), and the perceived number of side effects (12\%) as top reasons for not immunizing [13]. In a prevalence study for vaccine hesitancy among parents in the urban area of Western Bengal, India, indicated vaccine hesitancy prevalence of $29 \%$ [14], a result which was comparatively similar in a national study performed by Gust in Nigeria, where $28 \%$ of parents reported vaccine hesitancy, of which approximately two-thirds delayed or refused only certain vaccines [11].

According to the Strategic Advisory Group of Expert (SAGE) on immunization, the reasons for vaccine hesitancy fit into 3 categories: lack of confidence in effectiveness, safety, the system, or policy makers, complacency with perceived low risk of acquiring VPDs, and lack of convenience in the availability, accessibility, and appeal of immunization services, including time, place, language, and cultural contexts [1]. Consequently, challenges to maintaining adequate vaccine coverage include overcoming negative vaccine- and individual-specific attitudes and beliefs amidst a continual barrage of external factors such as vaccine controversies and evolving vaccination schedules that can also affect vaccination acceptance [15].

However, some parents are concerned about the cumulative pain and discomfort experienced by children who receive multiple shots at once, yet others worry about the potential health risks of receiving multiple vaccinations during one clinic visit, wondering whether the body can handle so many different antigens at once. In addition to that, parents' question whether the immune system may become overloaded by receipt of all the recommended vaccines during early childhood [16]. In some recent qualitative studies, it has been shown that mothers of infants who are afraid of vaccine adverse effects either decline or delay subsequent immunizations [17], yet results from earlier Qualitative studies have also suggested that vaccine-hesitant parents are significantly concerned about the immediate side effects of vaccines, such as redness, swelling or pain at the injection site [18]. The discomfort associated with vaccinations remains a significant barrier to vaccination, even as children age [15]. Although vaccines are well tolerated, no vaccine is entirely without risk, but due to lack of awareness, when children experience mild side effects, their mothers may refuse further immunizations [19, 20]. This vaccine refusal has been associated with outbreaks of invasive Haemophilus influenzae type $b$ disease, varicella, pneumococcal disease, measles, and pertussis, resulting in the unnecessary suffering of young children and waste of limited public health resources. Vaccine hesitancy is an extremely important issue that needs to be addressed because effective control of vaccine-preventable diseases generally requires indefinite maintenance of extremely high rates of timely vaccination $[2,15,20]$. This, therefore, calls for much-needed information about vaccines and safety. Although childhood immunizations are free in Uganda and many strategies like radio talk shows are done in a bid to change socio-cultural, religious beliefs and attitudes 
towards immunization and address vaccine hesitancy issues, and improve immunization coverage, there is little success [8, 21, 22], but only $55 \%$ of children aged $12-23$ months are fully vaccinated [23], yet the immunization agenda sets out seven priority areas and four core principles in, a world where everyone, everywhere, at every age, fully benefits from vaccines for good health and well-being [24].

Nansana Municipality is located in the Wakiso District of Central Uganda, in close proximity to Kampala City. It has a population of 532,800 people, with urban and peri-urban settlements. The municipality has persistently performed poorly with low routine immunization coverage and continues to frequently report outbreaks of vaccinepreventable diseases, especially measles. In the financial year 2018/19, the Municipality reported $41 \%$ and $42 \%$ coverage of Penta 3 and Measles vaccinations, respectively [25], which were far below the district performance at $82 \%$ and $87 \%$, respectively [26] and the national target of $>90 \%$ and $95 \%$ respectively [23], which could be due to increasing vaccine hesitancy.

In response to this, the current study explored the determinants of hesitancy to childhood immunizations of vaccinepreventable diseases in an urban setting like Nansana Municipality. The results of this study add to existing knowledge and guide policy makers to address the vaccine hesitancy issues to improve immunization programs in Uganda urban areas and sub-Saharan Africa and provide useful information for further research on these issues.

\section{Materials and Methods}

This was a cross-sectional mixed methods study using both quantitative and qualitative data collection methods, which was conducted between June and August 2021 in Nansana Municipality. The area is made up of four administrative divisions, namely, Nansana, Nabweru, Gombe, and Busukuma, and 29 parishes. It has 54 health facilities, with only $39 \%$ (21/54) of the health facilities having EPI services, while some of the remaining health facilities are used as outreach posts for EPI services [25].

The evaluation of the determinants of hesitancy to childhood immunization for vaccine-preventable diseases was carried out using researcher-administered questionnaires of 344 parents/guardians of children under 24 months. The sample size for quantitative data was estimated using the Kish Leslie formulae, 1965 of unknown population, [27] with vaccine hesitancy is estimated to be $29 \%$ [14]. Additionally, 2 focus group discussions of parents/guardians of children under 24 months from 2 randomly selected villages were all also conducted. The study employed simple random sampling strategies to identify respondents for the interviews. However, probability proportionate to size (PPS) was used for allocating the household according to the population of the divisions of Nansana Municipality, as shown in Table 1.

Table 1. Sample Size and Distribution among the Divisions of Nansana Municipality 2021

\begin{tabular}{|l|l|l|l|}
\hline Division & Number of Households & Percentage (\%) of HH & Sample Size \\
\hline Nansana & 52,725 & $39 \%$ & 134 \\
\hline Nabweru & 38,775 & $29 \%$ & 100 \\
\hline Gombe & 28,667 & $21 \%$ & 72 \\
\hline Busukuma & 14,444 & $11 \%$ & 38 \\
\hline Municipality & $\mathbf{1 3 3 , 2 0 0}$ & $\mathbf{1 0 0 \%}$ & $\mathbf{3 4 4}$ \\
\hline
\end{tabular}

A total of 2 focus group discussions from 2 randomly selected villages were conducted for parents/guardians of children $<24$ months. Each focus group had 8 participants (socially 
distanced, following the COVID-19 protocols to avoid it transmission), with each session taking 45 to 60 minutes.

\section{Participant Consent and Ethical Approvals}

Ethical approval was obtained from Mbarara University of Science and Technology, Research and Ethics Committee (MUST -REC, REF MUST-2021-68), and the Uganda National Council for Science and Technology (UNCST-REF HS1507ES). The clearance for conducting the research study in Nansana Municipality was sought and granted from Wakiso District Health Officer's office and the Nansana Municipal Council Town Clerk's office. All the participants were subjected to informed consent.

\section{Data Collection, Management, and Analysis}

Before data collection, the research instruments were pre-tested through the pilot study to determine suitability and appropriateness to ensure clarity and relevancy of data collection instruments. The structured questionnaire was adopted from the world health organization (WHO)-SAGE on vaccine hesitancy [28].

The content of the questionnaire included: socio-demographic variables, questions related to health services delivery in immunization context. Trained research assistants collected data under the guidance of the principal investigator.

Data was collected, cleaned, edited, and entered in SPSS version 20. Descriptive statistics were expressed as means/medians, frequencies, and percentages, whereas inferential statistics were analyzed using the Chi-square $\left(\chi^{2}\right)$ technique, where bivariate analysis was conducted to examine the association between the socio-demographics of parents, the health care system factors, and vaccine hesitancy. Crude Odds Ratios (COR) and corresponding 95\% Confidence Intervals
(CI) were reported. Significant variables (with a p-value $<0.05$ ) from the bivariate analysis were included in the models, the multivariate logistic regression to determine variables independently associated with vaccine hesitancy. Adjusted Odds Ratios (AOR) with corresponding 95\% CI were reported, and significance levels of $\mathrm{p}$ value $<0.05$ were used for hypothesis testing.

Qualitative data from the focus group discussions were captured as stated from the focus groups and key informants, transcribed and uploaded into the qualitative analysis software MAXQDA version 12. Data was analyzed following the six steps of the thematic approach developed by Braun and Clarke [29]. The data from the quantitative and qualitative analysis was triangulated. Data and information collected during the course of the study have been safely stored.

\section{Operational Definitions}

The following operational definitions were used:

\section{Hesitancy}

If the parent/guardian has ever been reluctant or hesitant to take the child for vaccination against the childhood vaccine-preventable diseases, he/she was considered having hesitancy.

\section{Refusal}

If the parents/guardian ever refused to take her or his child for immunization against the childhood vaccine-preventable diseases, he/she was considered a refusal.

\section{Results}

From the total of 344 sampled parents/guardians, the majority (72\%) had reached a secondary level of education or above, and more than $86 \%$ of the respondents were married or cohabiting. Most of the respondents $(81 \%)$ believed that immunization was beneficial for their children in preventing the occurrence and spread of diseases, and equally as many as $80 \%$ had some knowledge 
about childhood immunized diseases. The majority of the parents, $71 \%$, had a positive view of the health workers attitude, about $60 \%$ of them living within 2 kilometers from the health facility providing immunization services, and as many as $65 \%$ of the parents having had an experience with side effects from childhood immunization, though still a slight majority $58 \%$ appreciated that they had received adequate information about immunization for their children. The prevalence of vaccine hesitancy for childhood immunization among parents/guardians was found to be $27.6 \%$, while about $3 \%$ ever had a history of refusal to take their children for immunizations.

\section{Socio-Demographic Characteristics Determining Hesitancy to Childhood Immunizations}

Of the socio-demographic characteristics of the respondents, only the education level and the parent's belief in vaccine importance were found to be significantly associated with parental hesitancy to childhood immunizations, as shown in Table 2.

Table 2. Association between Socio-Demographic Factors and Vaccine Hesitancy in Bivariate Analysis, 2021

\begin{tabular}{|c|c|c|c|c|c|c|}
\hline \multirow[t]{3}{*}{ Variables } & \multicolumn{2}{|c|}{ Hesitancy to vaccinations } & \multirow[t]{3}{*}{$\chi^{2}$} & \multirow[t]{3}{*}{ df } & \multirow[t]{3}{*}{ p-value } & \multirow[t]{3}{*}{ COR; $(95 \% \mathrm{CI})$} \\
\hline & Yes & No & & & & \\
\hline & Freq $(\%)$ & Freq $(\%)$ & & & & \\
\hline \multicolumn{7}{|c|}{ Age of parent/guardian } \\
\hline$<25$ years & $38(27.1)$ & $108(72.9)$ & \multirow[t]{3}{*}{0.082} & \multirow[t]{3}{*}{2} & \multirow[t]{3}{*}{0.960} & \\
\hline $25-45$ years & $54(28.1)$ & $138(71.9)$ & & & & \\
\hline$>45$ years & $3(25.0)$ & $9(75.0)$ & & & & \\
\hline \multicolumn{7}{|c|}{ Gender of the parent/guardian } \\
\hline Male & $16(33.3)$ & $32(66.7)$ & \multirow[t]{2}{*}{0.912} & \multirow[t]{2}{*}{1} & \multirow[t]{2}{*}{0.340} & \\
\hline Female & $79(26.7)$ & $217(73.3)$ & & & & \\
\hline \multicolumn{7}{|l|}{ Education level } \\
\hline Never been to school & $6(85.7)$ & $1(14.3)$ & \multirow[t]{4}{*}{15.616} & \multirow[t]{4}{*}{3} & \multirow[t]{4}{*}{0.01} & \multirow[t]{4}{*}{$3.73(1.24-18.7)$} \\
\hline Primary $(\mathrm{P} 1-\mathrm{P} 7)$ & $22(24.4)$ & $68(75.6)$ & & & & \\
\hline Secondary (S1 - S6) & $54(28.4)$ & $136(71.6)$ & & & & \\
\hline Post-secondary & $15(26.3)$ & $42(73.7)$ & & & & \\
\hline \multicolumn{7}{|l|}{ Marital status } \\
\hline Never married & $4(16.0)$ & $21(84.0)$ & \multirow[t]{4}{*}{4.326} & \multirow[t]{4}{*}{3} & \multirow[t]{4}{*}{0.228} & \\
\hline Married/cohabiting & $86(29.1)$ & $210(70.1)$ & & & & \\
\hline Divorced/separated & $3(15.8)$ & $16(84.2)$ & & & & \\
\hline Widowed & $2(50.0)$ & $2(50.0)$ & & & & \\
\hline \multicolumn{7}{|l|}{ Religious affiliation } \\
\hline Catholic & $31(28.2)$ & $79(71.8)$ & \multirow[t]{6}{*}{4.458} & \multirow[t]{6}{*}{5} & \multirow[t]{6}{*}{0.486} & \\
\hline Protestant (Anglican) & $20(24.1)$ & $63(75.9)$ & & & & \\
\hline Muslim & $28(35.0)$ & $52(65.0)$ & & & & \\
\hline $\begin{array}{l}\text { Seventh Day } \\
\text { Adventist (SDA) }\end{array}$ & $4(16.0)$ & $21(84.0)$ & & & & \\
\hline Pentecostal & $11(26.2)$ & $31(73.8)$ & & & & \\
\hline Other religions & $1(25.0)$ & $3(75.0)$ & & & & \\
\hline \multicolumn{7}{|l|}{ Monthly Income } \\
\hline$<48$ USD & $21(32.3)$ & $44(67.7)$ & 1.222 & 2 & 0.543 & \\
\hline
\end{tabular}




\begin{tabular}{|c|c|c|c|c|c|c|}
\hline $49-143$ USD & $53(25.6)$ & $154(74.4)$ & & & & \\
\hline$>144$ USD & $21(29.2)$ & $51(70.8)$ & & & & \\
\hline \multicolumn{7}{|c|}{ Belief in vaccine importance } \\
\hline Yes & $54(19.4)$ & $225(80.6)$ & \multirow[t]{2}{*}{34.264} & \multirow[t]{2}{*}{1} & \multirow[t]{2}{*}{0.004} & \\
\hline No & $36(55.3)$ & $29(44.7)$ & & & & \\
\hline \multicolumn{7}{|c|}{ Knowledge of diseases } \\
\hline Yes & $71(25.8)$ & $204(74.2)$ & \multirow[t]{2}{*}{2.217} & \multirow[t]{2}{*}{1} & \multirow[t]{2}{*}{0.136} & \\
\hline No & $24(34.8)$ & $45(65.2)$ & & & & \\
\hline
\end{tabular}

The other socio-demographic variables, such as the age of the parent/guardian, gender of the parent/guardian, marital status, religion, monthly income, and knowledge of childhood immunized diseases, were found not to be determinants of hesitancy to childhood vaccinations against vaccine-preventable diseases.

Parents who had never received any formal education were about 4 times more likely to hesitate to take their children for immunization $(\mathrm{COR}=3.7,95 \%$ confidence interval, CI: 1.2 18.6), compared to those who had any formal education. On the other hand, parents who believed in vaccines protecting their children from the vaccine-preventable diseases were 3 times less likely to hesitate to take their children for immunization $(\mathrm{COR}=0.3,95 \% \mathrm{CI}$ : 0.1 - 0.7), compared to those who did not believe in vaccine importance, see Table 2 . Both factors retained their significance of determinants of hesitancy to childhood immunization after adjusting all other characteristics, as shown in Table 4.

\section{Health Care Delivery System Determinants of Parental Hesitancy to Childhood Immunizations}

There was significant association (p-value $<\mathbf{0 . 0 5})$ between some health service deliveryrelated factors to the parent's hesitancy to taking their children for immunization. These included health workers attitude (COR $=0.16$, $95 \%$ CI: $0.03-0.39$ ), availability of vaccines $(\mathrm{COR}=0.12, \quad 95 \% \quad \mathrm{CI}: \quad 0.04-0.42)$, accessibility to immunization services $(\mathrm{COR}=$ 0.22 , 95\% CI: $0.07-0.70)$, timing of the immunization clinic (COR=5.2, 95\% CI: $3.2-$ $8.7)$, side effects to vaccinations $(0.25,95 \% \mathrm{CI}$ : $0.08-0.79)$, and information provision on immunization $\quad(\mathrm{COR}=0.24,95 \%$ CI: $0.08-$ 0.69 ), were all significantly associated with hesitancy to childhood immunization, see Table 3.

Table 3. Association between Health Care System Factors and Vaccine Hesitancy in Bivariate Analysis, 2021

\begin{tabular}{|c|c|c|c|c|c|c|}
\hline \multirow[t]{3}{*}{ Variables } & \multicolumn{2}{|c|}{ Hesitant to vaccination } & \multirow[t]{3}{*}{$\chi^{2}$} & \multirow[t]{3}{*}{ df } & \multirow[t]{3}{*}{ p-value } & \multirow[t]{3}{*}{$\operatorname{COR}(95 \% \mathrm{CI})$} \\
\hline & Yes & No & & & & \\
\hline & Freq $(\%)$ & Freq $(\%)$ & & & & \\
\hline \multicolumn{7}{|l|}{ Attitude of health workers } \\
\hline Positive (Friendly) & $52(21.4)$ & $193(78.6)$ & \multirow[t]{2}{*}{20.856} & \multirow[t]{2}{*}{1} & \multirow[t]{2}{*}{0.000} & \multirow[t]{2}{*}{$0.16(0.06-0.39)$} \\
\hline Negative (Rude) & $34(34.4)$ & $65(65.6)$ & & & & \\
\hline \multicolumn{7}{|c|}{ Distance from the health facility } \\
\hline$<2$ kilometers & $47(22.8)$ & $159(77.2)$ & \multirow[t]{3}{*}{5.922} & \multirow[t]{3}{*}{2} & \multirow[t]{3}{*}{0.152} & \\
\hline $3-5$ kilometers & $38(34.9)$ & $71(65.1)$ & & & & \\
\hline$>5$ kilometers & $10(34.5)$ & $19(65.5)$ & & & & \\
\hline \multicolumn{7}{|l|}{ Availability of vaccines } \\
\hline Always available & $63(21.7)$ & $224(78.3)$ & \multirow[t]{2}{*}{26.740} & \multirow[t]{2}{*}{2} & \multirow[t]{2}{*}{0.012} & \multirow[t]{2}{*}{$0.12(0.04-0.42)$} \\
\hline Sometimes not all available & $24(47.9)$ & $26(52.1)$ & & & & \\
\hline
\end{tabular}




\begin{tabular}{|c|c|c|c|c|c|c|}
\hline Most times not any available & $3(42.9)$ & $4(57.1)$ & & & & \\
\hline \multicolumn{7}{|c|}{ Accessibility to immunization services } \\
\hline Yes & $70(23.1)$ & $235(76.9)$ & \multirow[t]{2}{*}{20.521} & \multirow[t]{2}{*}{1} & \multirow[t]{2}{*}{0.013} & \multirow[t]{2}{*}{$0.22(0.07-0.70)$} \\
\hline No & $21(52.6)$ & $18(47.4)$ & & & & \\
\hline \multicolumn{7}{|c|}{ Poor timing of immunization clinic } \\
\hline Yes & $58(53.7)$ & $50(46.2)$ & \multirow[t]{2}{*}{44.998} & \multirow[t]{2}{*}{1} & \multirow[t]{2}{*}{0.000} & \multirow[t]{2}{*}{$5.23(3.18-8.77)$} \\
\hline No & $44(18.6)$ & $192(81.4)$ & & & & \\
\hline \multicolumn{7}{|l|}{ Waiting time } \\
\hline$<3$ hours & $28(25.2)$ & $83(74.8)$ & \multirow[t]{3}{*}{1.459} & \multirow[t]{3}{*}{2} & \multirow[t]{3}{*}{0.482} & \\
\hline $4-5$ hours & $52(27.4)$ & $138(72.6)$ & & & & \\
\hline$>6$ hours & $15(34.9)$ & $28(65.1)$ & & & & \\
\hline \multicolumn{7}{|c|}{ Side effects after vaccinations } \\
\hline Yes & $72(32.3)$ & $151(67.7)$ & \multirow[t]{2}{*}{10.56} & \multirow[t]{2}{*}{1} & \multirow[t]{2}{*}{0.027} & \multirow[t]{2}{*}{$0.25(0.08-0.79)$} \\
\hline No & $28(22.9)$ & $93(77.1)$ & & & & \\
\hline \multicolumn{7}{|c|}{ Adequate information provision } \\
\hline Yes & $43(21.6)$ & $158(78.4)$ & \multirow[t]{2}{*}{16.301} & \multirow[t]{2}{*}{1} & \multirow[t]{2}{*}{0.018} & \multirow[t]{2}{*}{$0.24(0.08-0.69)$} \\
\hline No & $58(40.5)$ & $85(59.5)$ & & & & \\
\hline
\end{tabular}

Health worker's attitude, the timing of the immunization clinic, and adequate information provision all retained their significance of determinants of hesitancy to childhood immunization after adjusting all other characteristics as shown in Table 4. However, Other factors like distance from the health facility and waiting time were not significantly associated with vaccine hesitancy.

\section{Independent Determinants of Parental Vaccine Hesitancy to Childhood Immunizations}

In the final logistic regression model, education level, belief in vaccine importance, health workers attitude, the timing of immunization clinic, availability of vaccines, and adequate information provision were found to be independent determinants of hesitancy to childhood immunizations of vaccinepreventable diseases. Parents/guardians who had no formal education were 5 times more likely to hesitate to take their children for immunization (adjusted OR=4.9, 95\%CI: 2.6 29.5, $p=0.01$ ), compared to those who had attained a post-secondary level of education. Similarly, parents who viewed the timing of immunization services as poor were 3 times more likely to hesitate to take their children for immunization than those who did have a negative view of the immunization service's timing $(\mathrm{AOR}=3.4,95 \% \mathrm{CI}: 1.8-6.4, \mathrm{p}=0.01)$. On the other hand, parents/guardians who believed in vaccines protecting their children against the vaccine-preventable diseases were 2 times less likely to hesitate to take their children for vaccination $(\mathrm{AOR}=0.47,95 \% \mathrm{CI}$ : $0.17-0.97, \mathrm{p}=0.01$ ) compared to those who did not believe in vaccine importance, as well as those parents/guardians who had a positive view of health workers attitude being 5 times less likely to hesitate to take their children for vaccination compared to those who had a negative view of health workers attitude (AOR $=0.22$, 95\% CI: 0.06- 0.86, $\mathrm{p}=0.03)$. In the same vein, parents who thought they were provided with adequate information on immunization were about 2 times less likely to hesitate to take their children for vaccination (AOR=0.64, 95\% CI: $0.06-0.99, \mathrm{p}=0.04)$ compared to those who believed were not provided with adequate information concerning immunization as shown in Table 4. 
Table 4. Multivariate Logistic Regression showing the Association between Socio-Demographic and Health Care System Factors and Parental Vaccine Hesitancy, 2021

\begin{tabular}{|l|l|l|l|l|l|}
\hline \multirow{2}{*}{ Variable } & \multirow{2}{*}{ Response } & \multicolumn{2}{|l|}{ Hesitant to vaccination } & \multirow{2}{*}{ AOR $($ CI; 95\%) } & p=value \\
\cline { 3 - 4 } & & Yes & No & & \\
\cline { 3 - 4 } & & Freq (\%) & Freq (\%) & & \\
\hline Education level & Informal & $6(85.7)$ & $1(14.3)$ & $\mathbf{4 . 9 1}(\mathbf{2 . 6}-\mathbf{2 9 . 5})$ & $\mathbf{0 . 0 1 2}$ \\
\hline Belief in vaccine importance & Yes & $54(19.4)$ & $225(80.6)$ & $\mathbf{0 . 4 7}(\mathbf{0 . 1 7}-\mathbf{0 . 9 7})$ & $\mathbf{0 . 0 1 4}$ \\
\hline Attitude of health workers & Friendly & $52(21.4)$ & $193(78.6)$ & $\mathbf{0 . 2 2}(\mathbf{0 . 0 6}-\mathbf{0 . 8 6})$ & $\mathbf{0 . 0 3 1}$ \\
\hline Availability of vaccine's & Always & $63(21.7)$ & $224(78.3)$ & $1.09(0.23-5.22)$ & 0.912 \\
\hline Easy accessibility to services & Yes & $70(23.1)$ & $235(76.9)$ & $2.74(0.62-12.1)$ & 0.184 \\
\hline Poor timing of clinic & Yes & $58(53.7)$ & $50(46.2)$ & $\mathbf{3 . 4 0}(\mathbf{1 . 8 1}-\mathbf{6 . 3 5})$ & $\mathbf{0 . 0 1 0}$ \\
\hline Side effects from vaccinations & No & $28(22.9)$ & $93(77.1)$ & $1.01(0.17-6.06)$ & 0.99 \\
\hline Adequate information & Yes & $43(21.6)$ & $158(78.4)$ & $\mathbf{0 . 6 4 ( 0 . 1 6 - \mathbf { 0 . 9 9 } )}$ & $\mathbf{0 . 0 4 3}$ \\
\hline
\end{tabular}

\section{Key Findings from the Focus Groups}

About $94 \%$ of the focus group discussion participants were females of median age 29 years. The focus area for the group discussions included (but was not limited to) the following questions: Do you believe that vaccines can protect children from serious diseases? Do you think that most parents like you have their children vaccinated with all the recommended vaccines?

Have you ever been reluctant or hesitated to get a vaccination for your child? Have you ever refused vaccination for your child? Why do you think children are given vaccines/immunization; are there situations when you failed to bring your child for immunization and what were the reasons? Has distance, the timing of clinic, the time needed to get to a clinic or wait at the clinic and/or costs in getting to the clinic prevented you from getting your child immunized? Are there other pressures in your life that prevent you from getting your child immunized on time?

Parents/guardians expressed their concerns about the long waiting time, inadequate health worker staffing numbers, and sometimes missing vaccines due to stock-outs as significant gaps affecting immunization service delivery.
"Generally, the health workers are good, and I have no problem with them, only that they are few yet we are many mothers" "I have no issues with the nurses. They try their best, but they get tired because we many on that day. We get tired when we go as we wait for a very long time" FGD1.

"Sometimes we go, and they tell us the "drugs" are not available, that we should come back another time, the "drugs" for babies. Sometimes the nurse immunizing is not there. "Even me mine of 11months has just received it that of 9 months because when I went there the last time, I could not get. Then I had to first be sure before going back" "You can walk or get a motorcycle, yet when you reach there, they send you back" FGD2.

Respondents were asked about the side effects to childhood vaccinations, how often this happens?

"They usually have pain and fever. The injections are very painful. My child's thigh got swollen after the injection, I came to the nurse, and she told me that all will be well", (FGD1).

"We really need more information about side effects of vaccines to convince our husbands, because, if the child gets fever and cries, they refuse us to come back for another "dose" (FGD1)"We need more information from the health workers and VHTs why they our children all those injections", (FGD2). 
The religious issues concerning vaccines were also noted;

"Some of the parents refuse to take their children for vaccination because of their religious beliefs. "Some believe in no need of vaccines as God protects them".

The effect of Covid-19 have also been felt, leading to fear of mothers taking their children for immunization, compounded by travel restriction and increased transport cost as noted by some mothers;

"We fear this Covid disease which is killing many people, we shall wait till it safe to take our children for immunization" (FGD1). "The transport cost for the "boda boda" has doubled. I can't afford that now" (FGD2).

\section{Discussion}

The findings show that the major determinants of parental vaccine hesitancy to childhood immunizations against vaccinepreventable diseases in this urban context were; education level, belief in vaccine importance in protective the child against the preventable killer diseases, health workers attitude, the timing of clinic for immunization services and adequate information provision.

Parent's level of education impacts on understanding of issues and greatly influences their decisions to vaccinate their children or not. Consistent with several studies conducted elsewhere, parents with less or no formal education have greater distrust in the medical community, express more concerns about vaccine safety, and have less belief in the necessity and efficacy of vaccines [30-33]. However, in contrast to finding in this study, Opel et al. found that parents with higher levels of education were nearly four times as likely to be concerned about the safety of vaccines than those from lower education levels [30], giving mixed results on the level of education and it impacts on parental vaccine acceptance and uptake. In a SAGE group systematic reviews, having attained higher education status in India and Nigeria promoted parental vaccine acceptance, while in the USA, China, and Lebanon, parents with a higher level of education persistently had more doubts on vaccines compared to those with lower education levels [34].

Parent's belief in vaccines' effectiveness and safety promotes trust, improves individual attitude, and reduces vaccine hesitancy. Consistent with studies conducted elsewhere, parents who have faith in vaccines protecting their children against the VPDs are more likely to have immunization acceptance and uptake of immunization [1, 13, 15]. A study done in Nigeria reported that parents who individually believe in vaccine effectiveness and safety take their children for vaccination more consistently and complete their immunization schedules [20]. In the current study, the variation in believing in different types of vaccines' effectiveness in protecting the children might have impacted the results. However, information on the belief in different vaccine antigen effectiveness was not collected and is an area for further investigation.

When the health worker's attitude is deemed as friendly by the parents/guardians positively impacts on parent's acceptance of immunization programs and therefore reduces on vaccine hesitancy. This consequently promotes a healthy parent-to-health worker relationship, resulting in addressing issues like the importance of completing the immunization schedule and the safety of vaccines [1, 28, 35]. According to [36], the study showed that parents who reported that their vaccination decisions were positively influenced by healthcare providers were also more likely to believe that vaccines were safe. In fact, parents with lower levels of trust in their child's doctor also have lower confidence in the safety of vaccines and therefore hesitate to vaccinate their children [32].

The convenience of the immunization services clinic also impacts on parents' access to immunization services, which, when is good, greatly reduces on hesitancy of parents to take 
their children vaccination which improves childhood immunization uptake and completion of the immunization schedule $[15,17]$. On the other hand, lack of convenience by parents and poor accessibility to immunization services greatly increases parental hesitancy to their children immunization $[1,28]$. The frustration from parents because of the long waiting time negatively impacts their decisions to take their children to the health facility for immunization [19]. They would rather stay home or attend to the immediate financial needs, rather than endure the long waiting time of 4-7 hours, including the travel to and from the health facility, yet they have their businesses and other competing needs to attend to Abdulraheem 2011 [20]. This would indirectly contribute to a delay in the schedule for the affected children because these parents/guardians may hesitate to return on the next rescheduled date. This calls for appropriate area-specific planning and local research within the division to find the ways to reach to these vulnerable children for protection against these vaccine preventable diseases in order to achieve the IA2030 [24].

Good communication leads to understanding and sharing of information. Adequate information provision, therefore, promotes vaccine acceptance and greatly reduces on vaccine hesitancy. In a study by Smith et al., effective communication and vital information sharing to parents reduce parental concerns about vaccine safety and side effects [36] and negative rumors about the vaccines [37]. When the parents are not given adequate information are more likely to hesitate to take their children for vaccination, despite overwhelmingly believing in vaccines protecting their children against the diseases [9]. Well-informed parents are likely to understand the importance of honoring the return dates and completing the immunization schedule [21]. As indicated in the focus group discussions, the parents need more adequate information on how to address the side effects.
The prevalence of $27.6 \%$ for parental hesitancy towards childhood immunization found in this study, does explain in part why immunization uptake is low in Nansana Municipality [25] and frequent outbreaks of measles in the area. A comparable study done in India from an urban of West Bangal had hesitancy marginally higher at 29\% Sikder2020 [14], while from another study from Nigeria it was $28 \%$ [11]. The refusal parents prevalence of $3 \%$ was slightly higher than a previous study result of $1-2 \%$ from the USA, $[9,15]$.

In contrast to the findings of a review of studies conducted elsewhere, parents age, gender, religion, income, marital status, knowledge of vaccines, distance to the immunization center, and waiting time were not found to be associated with vaccine hesitancy $[34,37,38]$. In other studies, Parents of lowerincome brackets have greater levels of concern about the safety and necessity of vaccines as compared with those of higher income [30-32, 39]. However, socioeconomic factors appear to have conflicting associations with parental immunization acceptance, which could reflect differences in underlying beliefs about vaccines that differ by socioeconomic strata [15].

Availability of vaccines and side effects of vaccines were not independently associated with parental vaccine hesitancy. The availability of vaccine issues could be attributed to easy accessibility to other immunization centers since over $90 \%$ of parents live within a 5-kilometer distance from the health facility offering EPI services. On the other hand, the issue of side effects not being independently associated with vaccine hesitancy could probably be because, although some parents/guardians may get side effects or reactions to vaccines, they might have been given information about expected reactions to vaccinations like fever and pain at the site and therefore cannot hinder them taking their children for vaccination, which makes it of less importance. In contrast to studies elsewhere, the side effects of vaccines frequently and 
consistently were the major independent determinants to parental vaccine hesitancy [20, 34, 37, 40]. Side effects from vaccinations negatively affect parents decisions to delay or stop the immunization of their children $[16,17$, 20].

Admittedly, however, as reported by SAGE, very few studies on vaccine hesitancy have been conducted in African compared to the Americas and Europe, yet the burden of unimmunized children as high as over $80 \%$ are from Africa [34]. In fact, little is known about the nature and causes of vaccine hesitancy in Africa, with most research in this area conducted in high-income countries [41]. A few of the studies conducted in Kenya, Malawi, and Ethiopia [37], and Nigeria [34], mostly use models developed in Western countries, which may not be suitable for African populations.

The impact of misinformation about childhood immunization on social media platforms and how they can affect parental vaccine hesitancy in an urban settlement have not been explored by this study and therefore recommended for further research.

\section{Study Limitations}

Although the study was confined to one municipality, this study area is typical of other urban settings in terms of health infrastructure and in Uganda. The study findings are therefore comparable across similar settings. We also note that this was a cross-sectional study and therefore, we cannot define the temporal relationship between the independent variables and outcome.

The direction of causality can therefore only be regarded as suggestive. The data collected on a number of independent variables were based on self-reports that are likely to be subject to social desirability bias. As a result, there is a limit to which such responses can be considered accurate by foreknowledge of what, in the view of the respondent, would be a suitable response. However, the current findings do carry implications for health service managers, decision-makers, and health care providers in their consideration of designing the measures to address parental hesitancy to childhood vaccinations against vaccinepreventable diseases.

\section{Conclusion}

The parental vaccine hesitancy prevalence rate is comparatively similar to previous urban area studies.

Although parents overwhelmingly share the belief that vaccines are a good way to protect their children from vaccine-preventable disease, these same parents express concerns regarding the convenience of the immunization clinic services and side effects of vaccines. Even though the information is available to address the many vaccine safety concerns, such information is not reaching many parents in an effective manner.

\section{Appendices}

\section{Abbreviations}

$\begin{array}{lll}\text { AOR } & : \text { Adjusted Odds Ratio } \\ \text { COR } & : \text { Crude Odds Ratio } \\ \text { COVID-19 } & : \text { Corana Virus Disease -2019 } \\ \text { CI } & : \text { confidence interval } \\ \text { FGD } & : \text { Focus Group Discussion } \\ \text { IA2030 } & : \text { Immunization Agenda 2030 } \\ \text { SPSS } & : \text { Statistical Package for Social Sciences } \\ \text { WHO } & : \text { World Health Organization }\end{array}$

\section{Consent for publication}

Not applicable.

\section{Availability of Data and Materials}

All data supporting our findings are contained in the paper. There are no restrictions to data sources.

\section{Competing interests}

The authors declare that there are no competing interests.

\section{Funding}

The study was self-sponsored. 


\section{Acknowledgements}

All participants in this study

\section{References}

[1] MacDonald, N. E, 2015 "Vaccine hesitancy: Definition, scope, and determinants," Vaccine, 33(34), 4161-4164, https://doi.org/10.1016/j.vaccine.2015.04.036.

[2] Salmon, D. A., Dudley, M. Z., Glanz, J. M, and S. B. Omer, S. B, 2015 "Vaccine hesitancy: Causes, consequences, and a call to action," Vaccine, vol. 33, D66-D71.

https://doi.org/10.1016/j.vaccine.2015.09.035.

[3] World Health Organization, 2018 "World health statistics 2018: monitoring health for the SDGs, sustainable development goals: World Health Organization," Geneva, Switzerland, https://creativecommons.org/licenses/by-ncsa/3.0/igo.

[4] Tadesse, H., Deribew, A and Woldie, M, 2009 "Predictors of defaulting from completion of child immunization in south Ethiopia, May 2008 A case control study," BMC Public Health, vol. 9, 4-9, https://doi.org/10.1186/1471-2458-9-150.

[5] World Health Organization, 2009 "World Health Statistics," WHO Library Cataloguing-inPublication Data Geneva, World Health Organization, Geneva, Switzerland.

[6] Wolfson et al., 2008 "Estimating the costs of achieving the WHO - UNICEF Global Immunization Vision and Strategy, 2006 - 2015," https://doi.org/10.2471/BLT.07.045096.

[7] World Health Organization, 2021"World Health Statistics," World Health Organization, Geneva, Switzerland,

https://creativecommons.org/licenses/by-ncsa/3.0/igo.

[8] Rutherford, M. E., Mulholland, K and Hill, P. C, 2010 "How access to health care relates to underfive mortality in sub-Saharan Africa: systematic review," Trop. Med. Int. Heal., 15(5), 508-519, https://doi.org/10.1111/j.1365-3156.2010.02497.x.

[9] Freed, G. L., Clark, S. J., Butchart, A. T., Singer, D. C, and Matthew, M, 2010 "Parental Vaccine (parents/guardians, Nansana Municipal Council health team, and the Research assistants).
Safety Concerns in 2009 Parental Vaccine Safety Concerns" Off. J. Am. Acad. Pediatr, DOI: 10.1542/peds.2009-1962.

[10] Schaffer, S. E., Singer, D., Butchart, A. T and M. Davis, M, 2011 "Alternative Vaccination Schedule Preferences Among Parents of Young Children," Vaccines, https://doi.org/10.1542/peds.2011-0400.

[11] Gust, D. A., Darling, N., Kennedy, A and Schwartz, B, 2021 "Parents with Doubts About Vaccines: Which Vaccines," vol 3, https://doi.org/10.1542/peds.2007-0538.

[12]Dubé et al., 2013 "Vaccine hesitancy an overview," Hum. Vaccine. Immunother., vol. 5515, https://doi.org/10.4161/hv.24657.

[13] Guay, M., Dubé, E and Laberge, C, 2018 "A Portrait of Vaccine-Hesitant Canadians," in Public Health in the Age of Anxiety, University of Toronto Press, pp. 165-194. https://doi.org/10.3138/9781487510404-008.

[14]Sikder et al., 2020 "Prevalence of vaccine hesitancy and its associated factors in an urban area of West Bengal, India," Int. J. Community Med. Public $\quad H e a l ., \quad 7 \quad$ (9), 43-49, http://dx.doi.org/10.18203/2394-

6040.ijcmph20203905.

[15] Gowda, C, and Dempsey, A. F, 2013 "The rise (and fall?) of parental vaccine hesitancy," Hum. Vaccine. Immunother., vol. 5515, https://doi.org/10.4161/hv.25085.

[16] Williams, S. E, 2014 "What are the factors that contribute to parental vaccine-hesitancy and what can we do about it?" Hum. Vaccine. Immunother., vol. 5515, https://doi.org/10.4161/hv.28596.

[17] McClure, C. C., Cataldi, J. R and S. T. O'Leary, S. T. O, 2017 "Vaccine Hesitancy: Where We Are and Where We Are Going," Clin. Ther., 39 (8), 1550-1562,

https://doi.org/10.1016/j.clinthera.2017.07.003.

[18] Shui, I., Kennedy, A., Wooten, K and Schwartz, B, 2005 "Factors Influencing African-American Mothers' Concerns about Immunization Safety: A 
Summary of Focus Group Findings," Atlanta Georgia, PMID: 15926642.

[19] Al-moukhtar, O and Al-, O, 2011 "Knowledge, attitude and practices of mothers regarding immunization of infants and preschool children at Al-Beida City, Libya 2008,” Egypt J Pediatr Allergy Immunol, 9 (1), 29-34.

[20] Abdulraheem, L. S., Onajole, A. T., Jimoh, A. A. G and Oladipo, A. R, 2011 "Reasons for incomplete vaccination and factors for missed opportunities among rural Nigerian children," J. Public Heal. Epidemiol., vol. 3, April 194-203, http://www.academicjournals.org/jphe.

[21]Malande et al., 2019 "Barriers to effective uptake and provision of immunization in a rural district in Uganda," PLoS One, 14 (2), e0212270, 14 (2), p. e0212270, https://doi.org/10.1371/journal.pone.0212270.

[22] Maina, J., Karanja, L. C \& Kombich, S, 2013 "Immunization coverage and its determinants among children aged 12 - 23 months in a peri-urban area of Kenya.," vol. 8688, $1-7$, https://doi.org/10.11604/pamj.2013.14.3.2181.

[23] Ministry of Health, "Health Annual health Sector Performance Report," 2019. Ministry of Health: Kampala, Uganda.

[24] O'Brien, K., Lindstrand, A and Nandy, R, 2021 "The Immunization Agenda 2030: a vision of global impact, reaching all, grounded in the realities of a changing world,"

http://dx.doi.org/10.2139/ssrn.3830709.

[25]Nansana Municipal Council, HMIS Report 2019 "Nansana Municipality Health Records." Municipal Health Office, Nansana, Uganda.

[26] Wakiso District Local Government, HMIS Report 2019 "Wakiso District Health Records." District Health Officer, Wakiso, Uganda.

[27] Pourhoseingholi, M.A., M. Vahedi, M and M. Rahimzadeh, M, 2013 "Sample size calculation in medical studies," 6 (1), 14-17, PMID: 24834239.

[28] World Health Organization, 2014 "Report of the Sage Working Group on Vaccine Hesitancy," http://www.who.int/immunization/sage/sage_wg_va ccine_hesitancy_apr12/en/.

[29] Braun, V, 2014 "What can " thematic analysis", offer health and well-being researchers?" Int J
Qualitative Stud Health Well-being, 1, 9-10, http://dx.doi.org/10.3402/qhw.v9.26152.

[30] Opel et al., 2011 "Validity, and reliability of a survey to identify vaccine-hesitant parents," Vaccine, $29 \quad$ (38), 6598-6605, https://doi.org/10.1016/j.vaccine.2011.06.115.

[31] Shui, I. M., Weintraub, E. S and Gust, D. A, 2006 "Parents concerned about vaccine safety: differences in race/ethnicity and attitudes," Am. J. Prev. Med., 31 (3), 244-251, https://doi.org/10.1016/j.amepre.2006.04.006.

[32] Gust, D. A., Woodruff, R., Kennedy, A., Brown, C., Sheedy, K and Hibbs, B, 2003 "Parental perceptions surrounding risks and benefits of immunization," in Seminars in pediatric infectious diseases, 2003, $14 \quad$ (3), 207-212, https://doi.org/10.1016/S1045-1870(03)00035-9.

[33] Gust, D. A., A. Kennedy, A., Shui, I., Smith, P. J., Nowak, G and Pickering, L. K, 2005 "Parent attitudes toward immunizations and healthcare providers: the role of information," Am. J. Prev. Med., $29 \quad$ (2), 105-112, https://doi.org/10.1016/j.amepre.2005.04.010\.

[34] Sadaf, A., Richards, J. L., Glanz, J., Salmon, D. A, and S. B. Omer, S. B, 2013 “A systematic review of interventions for reducing parental vaccine refusal and vaccine hesitancy," Vaccine, 31 (40), 42934304, https://doi.org/10.1016/j.vaccine.2013.07.013. [35]Olson, O, and Berry, C, 2020 "Addressing Parental Vaccine Hesitancy towards Childhood Vaccines in the United States: A Systematic Literature Review of Communication Interventions and Strategies," $\quad$ Vaccine, 2020, https://doi.org/10.3390/vaccines8040590.

[36] Smith, P. J., Kennedy, A. M., Wooten, K., Gust, D. A and Pickering, L. K, 2006 "Association between health care providers' influence on parents who have concerns about vaccine safety and vaccination coverage," Pediatrics, 118 (5), e1287e1292, https://doi.org/10.1542/peds.2006-0923.

[37]Adamu et al., 2021 "Drivers of hesitancy towards recommended childhood vaccines in African settings: a scoping review of literature from Kenya, Malawi, and Ethiopia," Expert Rev. Vaccines, $20 \quad$ (5), 611-621, https://.doi.org/10.1080/14760584.2021.1899819. 
[38] Azizi, F. S. M., Kew, Y and Moy, F. M, 2017 "Vaccine hesitancy among parents in a multi-ethnic country, Malaysia,” Vaccine, 35 (22), 2955-2961, https://doi.org/10.1016/j.vaccine.2017.04.010.

[39] Kennedy, A. M., Brown, C. J and D. A. Gust, D. A, 2005 "Vaccine beliefs of parents who oppose compulsory vaccination," Public Health Rep., 120 (3), 252-258, https://doi.org/10.1177/003335490512000306.

[40] Giambi et al., 2018 "Parental vaccine hesitancy in Italy - Results from a national survey," Vaccine,
36 (6), 779-787, https://doi.org/10.1016/j.vaccine.2017.12.074. [41] Cooper, S., Betsch, C., Sambala, E Z., Mchiza, $\mathrm{N}$ and Wiysonge, C. S, 2018 "Vaccine hesitancy-a potential threat to the achievements of vaccination programmes in Africa," Hum. Vaccine. Immunother, $14 \quad$ (10), 2355-2357, https://doi.org/10.1080/21645515.2018.1460987.w. 